\title{
Patent Harcamaları ve İktisadi Büyüme Arasındaki İlişki: Türkiye Örneği
}

Cem IŞIK

isikc@atauni.edu.tr

\section{The Relationship of Patent Expenditure and Economic Growth: The Case of Turkey}

\begin{abstract}
Patent rights, which form a basis in achieving a new technological development by researching and improving the current technology, make a great contribution to the economy of a country in respect to the application of innovations and inventions to the industry. This study aims at analyzing the importance of patent rights for the economic growth of Turkey and contributing the economic policies that will be established in this direction. In this context, the patent expenses of Turkey between the dates 1990:1-2010:4 and economic growth variables are analyzed by various methods (by Granger cointegration models and scale). The results show a uni-directional relationship between patent expenses and economic growth.
\end{abstract}

Keywords

JEL Classification Codes : C22, O3.
: Patent Expenses, Economic Growth, Granger Cointegration.

\section{Özet}

Mevcut teknolojiyi araştırıp, geliştirerek yeni bir teknolojik gelişmenin yakalanmasında temel teşkil eden patent hakları; yeniliklerin ve yeni buluşların sanayide uygulanması açısından ülke ekonomisinin gelişmesine önemli katkıda bulunmaktadır. Bu çalışma ile ülkemiz öznelinde patent haklarının ekonomik büyüme üzerindeki etkisinin analiz edilmesi ve bu doğrultuda oluşturulacak ekonomik politikalara katkıda bulunulması amaçlanmıştır. Bu kapsamda, Türkiye’nin 1990:1-2010:4 yıllarını kapsayan dönemine ilişkin patent harcamaları ve ekonomik büyüme değişkenleri çeşitli yöntemler ile (nedensellik ve eş-bütünleşme gibi) analiz edilmiştir. Elde edilen sonuçlar patent harcamaları ve ekonomik büyüme arasında tek yönlü bir nedensellik ilişkisini göstermektedir. 
Cem IŞIK 


\section{Giriş}

Bugün kâr marjlarının artmasına paralel olarak taklitçiliğin yaygınlaşması gelişmiş ülkeleri bu tür ihlalleri engellemek adına fikri mülkiyete konu olan buluşları, özgün tasarımları, markaları, yazılımları, sinema ve müzik, ilim ve edebiyat eserlerini uluslararası boyutta korumak için bir takım anlaşmalara taraf olmaya itmektedir. $\mathrm{Bu}$ amaçla, uluslararası rekabetin korunması ve güçlendirilmesi amacıyla patent haklarının güvence altına alınması, yenilikçiliği ve gelişim hızının artırılması önem arz etmektedir. Fikri mülkiyet hakları fikri üretimi özendirmeyi amaçlarken ekonomik, sosyal ve kültürel ilerlemeyi de tesis etmek amacı taşımaktadır. Böylece, etkin bir fikri mülkiyet korumasının varlığı, araştırma-geliştirme yatırımına teşvik, yenicilikçiliği özendirmek ve yabancı sermayeyi çekebilmek için gerekli olan şartlardan biridir (Avrupa Birliği ve Sağlık Bakanlığı Uyum Çalışmaları, 2010). Bir fikrin Ar\&Ge ve yenilik çalışmalarıyla desteklenerek patentinin alınmasına ilişkin süreç Şekil: 1 ile gösterilmiştir.

Şekil: 1

\section{Patent'in Ortaya Çıkış Süreci}

\section{Fikir}

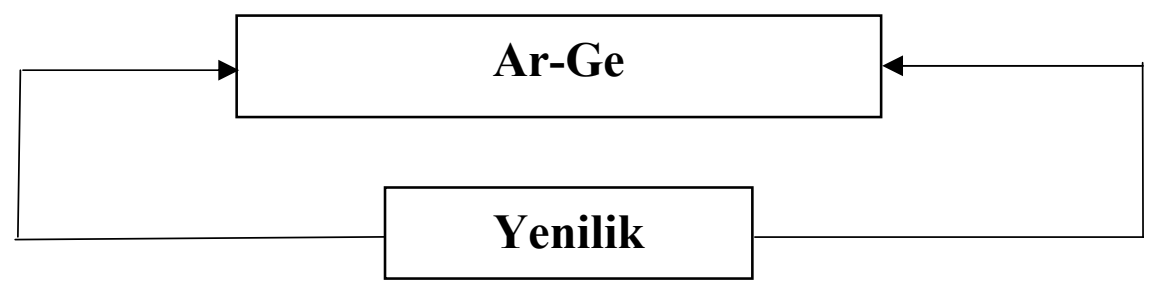

\section{Patent}

Kaynak: Ahmet Ayhan, 2002: 264.

Yeni fikirlerin patent ile korunmasına ilişkin yasal düzenlemelerin ilki 1474 yılında Venedik'te uygulanan patent kanunudur (Güçer, 2005). Dünyada ilk patent 1552 yılında İngiltere'de "boyalı cam pencerelerinin üretim şekli" için verilmiştir. Bundan sonra 1624 yllında yine İngiltere'de, 1790 yılında ABD'de, 1791 y1lında Fransa'da, 1877 y1lında Almanya'da ve 1879 yılında Osmanlı İmparatorluğu'nda yürürlüğe giren patent kanunları, Dünyada patent sistemine ilişkin yasal uygulamaların ilk örneklerini teşkil etmektedir (Yalçıner, 2004). 
Uluslararası ticaretin yaygınlaşmasıyla fikirlerin tanınması, buluş sahibinin ödüllendirilmesi, yenililik faaliyetlerinin özendirilmesi ve Ar\&Ge sonuçlarına dayanarak teknik bilginin yaygınlaşmaya başlaması sonucu ortaya çıkan patent kanunları, "Patent İşbirliği Anlaşması” (1970) ve hemen ardından "Avrupa Patent Anlaşması" (1973) gibi yeni oluşumlarla ülkesel sınırları aşmış ve uluslararası bir boyut kazanmıştır. Ülkemizde ise patent sisteminin temeli 23 Mart 1879 tarihinde Paris Anlaşması ile1 atılmıştır. İlk üyeliğimiz 1925 tarihinde gerçekleşmiş ve son olarak katılım tarihimiz ise 01.02.1995'tir (Soyak, 2005).

Bilgi çağının en önemli unsurlarından biri bilgidir. Bilgiyi koruyucu düzenlemelere gidilmesi, fikri ve sınaî mülkiyet hukuku ile sağlanmıştır. Fikri ve sınaî mülkiyet kavramı; patentler, faydalı modeller, markalar, endüstriyel tasarımlar, fikir ve sanat eserleri, coğrafi işaretler, ticaret unvanları, firma adları ve hatta gizli bilgileri kapsayacak kadar geniş bir anlama sahiptir. Dünya Ticaret Örgütünü kuran 1995 tarihli "Ticaretle Bağlantılı Fikri Mülkiyet Hakları Anlaşması" (TRIPS), -ekonomideki payına bağlı olarak- özgün fikirleri, fikri ve sınaî mülkiyet hakkı kapsamında hukuki koruma altına alan temel bir anlaşmadır. Ülkemizde fikri ve sınaî mülkiyet haklarının korunması açısından AB Ortaklık Konseyi’nin 1/95 sayılı Kararı önemli bir kilometre taşıdır (Soyak, 2005).

İhtira Beratı Kanunu ile 1879 tarihinde ülkemizde uygulanmaya başlayan patent koruması, 1995 yılına kadar aynı şekilde devam etmiştir. 116 yıl boyunca uygulanan bu patent kanunlarından sonra, nihayet 1995 yll itibariyle modern bir patent sistemine geçilmiştir. Dünyada ise ABD, İngiltere, Fransa, Rusya ve Japonya gibi gelişmiş ülkeler patent korumasına ilişkin hukuk sistemlerini 1800 'lü yıllarında oluşturmuşlardır. Patent ülke ekonomisinin gelişmesine katkıda bulunan önemli öğelerden biridir (Acar ve Yeğenoğlu, 2004).

Yeniliklerin ve yeni buluşların sanayide uygulanması ülke ekonomisinin gelişmesinde önemli bir rol oynamaktadır. Buluş sahibinin ödüllendirilmesi ve özendirilmesi önemli olmakla birlikte öncelikle doğru işleyen bir patent sisteminin oluşturulması gerekmektedir. Buluş sahibinin buluşu karşıllğında söz konusu ürünü üretmeye, satmaya ve kullandırmaya belirli bir süre ayrıcalık veren uygulamalar, bugün çoğu ülke tarafından kabul edilmektedir. Dolayısıyla bir buluşun, bir yeniliğin buluş sahibinin rızası ve izni dışında diğer kişiler tarafından kullanılmamasını sağlamak, o yenilik için patent başvurusu yapılmasının sebebidir (Abacıoğlu ve Dikmen, 2005).

1 “Paris Anlaşması”, Sinaî Mülkiyetin Himayesine Mahsus Milletlerarası Bir İttihat İhdas Edilmesine Dair 20 Mart 1883 tarihli bir mukavele olup sinâ̂ veya ticari faaliyette bulunan gerçek veya tüzel kişilerin fikri mülkiyetlerinin koruması amaçlı yapılan bir sözleşmedir. 
Patent sistemi buluşa dayanmaktadır. Buluş adından da anlaşılacağı üzere bulmayla ilgili bir kavram olmakla birlikte esas olarak doğada mevcut olan teknik ya da bir kuralın ortaya çıkmasıdır. Buluş "tarım dâhil, sanayideki herhangi bir spesifik sorununun çözümü” olarak ifade edilmektedir(Abacıoğlu ve Dikmen, 2005).

Buluşların patent verilerek korunmasındaki esas amaç, buluş faaliyetlerini özendirmek ve buluşlarla elde edilen teknik çözümlerin sanayiye intikalini ve uygulanmasını sağlamak, buluşların başkaları tarafından öğrenilerek geliştirilebilmesine olanak yaratmaktır (Yalçıner, 2004).

Buluşların patent gibi hukuki bir düzenlemeyle korunmadığı durumlarda, buluş sahibinin bu iş için harcadığı emek ve gerçekleştirdiği harcamaların heba olduğu ortadadır. Patent niteliğinde bir hukuki korumanın olmadığı bir ekonomik düzende, buluş sahibi ve rakipleri ürünü rekabetçi bir fiyatla satabilecektir. Böyle bir durum insanların buluş yapmasını engelleyen faktörlerden biridir. Patent hakkı, teknolojik yenilikleri araştırma ve geliştirme faaliyetlerinde emek sarf edenlerin çıkarlarını koruyan bir haktır. Patentlerin en genel işlevlerinden biri var olan bilginin topluma yayılmasıdır. Patentler aslında toplumla birey arasındaki alışverişi ifade etmektedir. Buluş sahibi, buluşu üzerinde bir takım haklara sahiptir. Bu yüzden patente dayalı koruma sisteminin gelişmiş olması, yabancı yatırımların artmasını sağlamaktadır. Patent sistemi, buluş sahiplerinin haklarının tam olarak güvence altına alınması ve böylece o ülkede yatırım yapacak yabancı sermayeye güven aşılanmasını sağlamaktadır (Gümüş, 2010).

Patent veya faydalı model başvurusu yapıldıktan sonra ürün tanıtımları ve endüstriyel uygulamalar yapılarak belge alınıncaya kadar, geçici bir koruma sağlanmaktadır. Başvurunun yapılması, patent veya faydalı model belgesinin düzenlenmesini beklemeden, söz konusu buluşun açıklanabilmesine yardımcı olmaktadır. Patent belgesinin düzenlenmesi yaklaşık 30 aylık bir süreç içinde gerçekleşeceğinden, buluş konusu ürünün üretilmesi veya buluş konusu yöntemin uygulanması başvurudan sonra olabilmektedir (Dericioğlu, 2010).

Patent araştırması yapılmasının amaçları aşağıdaki gibi sıralanabilir (Correa, 2000):

- Bir buluşun karşılaştırılması amacıyla önceki patent başvurusunun ve/veya patent metinlerinin saptanmas1,

- Yeni üretilecek bir ürünün patentle korunan bir buluş ile çakışıp çakışmadığının saptanması,

- Rakiplerin patent başvuruları veya aldıkları patentlerin saptanması,

- Patent başvurusunu hazırlamaya başlamadan önce buluş ile ilgili teknik bir alanda önceki tekniğin öğrenilmesidir. 
10.01.2008 tarihli “60. hükümet programı eylem planını” açıklayan Başbakan Tayyip Erdoğan, "Maastricht kriterleri” başlıklı konuşmasında fikri hakların önemini şu şekilde vurgulamıştır (Resmi Gazete, 2007):

"Haksız rekabetin önlendiği, fikri hakların korunduğu, tüketici haklarının ihlal edilmediği, sözleşmelerin uygulandiğg bir ortamda, belirsizlikler azalacak, güvenilirlik ve öngörülebilirlik să̆lanacak, böylece yatırım, istihdam ve üretim artacaktır."

Aşağıda yer alan Tablo: 1 Türkiye'nin taraf olduğu uluslararası patent anlaşmalarını göstermektedir.

Tablo: 1

Türkiye'nin Taraf Olduğu Uluslararası Patent Anlaşmaları

\begin{tabular}{lcc}
\hline Türkiye'nin Taraf Olduğu Uluslararası Anlaşmalar & $\begin{array}{c}\text { İlk İmza } \\
\text { Tarihi }\end{array}$ & $\begin{array}{c}\text { Üye } \\
\text { Sayısı }\end{array}$ \\
\hline \hline Dünya Fikri Mülkiyet Teşkilatı WIPO Kuruluş Sözleşmesi & 1967 & 184 \\
Dünya Ticaret Örgütü (WTO) Kuruluş Anlaşması & 1995 & 150 \\
Avrupa Patent Sözleşmesi (EPC) & 1973 & 31 \\
\hline \hline Sınai Mülkiyetin Korumasına Dair PARIS Sözleşmesi & 1883 & 171 \\
Patent Kanunu Antlaşması (PLT) & 2000 & 14 \\
Marka Kanunu Antlaşması (TLT) & 1994 & 38 \\
Marka Kanununa İlişkin Singapur Antlaşması & 2006 & \\
\hline \hline Mikroorganizmaların Uluslararası Saklanmasına İlişkin Budapeşte Antlaşması & 1977 & 66 \\
Tasarımların Uluslararası Tesciline İlişsin LAHEY Anlaşması (Cenevre Metni) & 1999 & 45 \\
Madrid Anlaşması'na İlişkin Protokol & 1989 & 72 \\
Patent İşbirliği Antlaşması (PCT) & 1970 & 136 \\
\hline \hline Tasarımların Sınıflandırılmasına İlişkin LOCARNO Anlaşması & 1968 & 48 \\
Marka Tescilinde Eşyaların ve Hizmetlerin Uluslararası Sınıflandırmasına İlişkin Nís & 1957 & 80 \\
Anlaşması & 1971 & 57 \\
Patentlerin Uluslararası Sınıflandırmasına İlişkin Strasburg Anlaşması (IPC) & 1973 & 23 \\
Markaların Figüratif Elemanlarının Sınıflandırılmasına İlişkin Viyana Anlaşması & &
\end{tabular}

1990-2010 yıllarını kapsayan döneme ilişkin Türkiye Patent Enstitüsüne yapılan yerli ve yabancı patent başvuruları Tablo: 2'de ve dünyada uluslararası patent başvurusu yapan ilk 20 firma ise Tablo: 3 'te verilmiştir. 
Tablo: 2

Türkiye’de Yıllara Göre Patent Başvuruları (1990-2010)

\begin{tabular}{cccc}
\hline Yll & Yerli & Yabanci & Toplam \\
\hline \hline 1990 & 138 & 1090 & 1228 \\
1991 & 136 & 1073 & 1209 \\
1992 & 190 & 1062 & 1239 \\
1993 & 168 & 1071 & 1392 \\
1994 & 148 & 1244 & 1690 \\
1995 & 170 & 1520 & 902 \\
1996 & 189 & 713 & 1531 \\
1997 & 203 & 1328 & 2483 \\
1998 & 207 & 2276 & 3020 \\
1999 & 276 & 2744 & 3433 \\
2000 & 277 & 3156 & 3214 \\
2001 & 337 & 2877 & 1874 \\
2002 & 414 & 1460 & 1152 \\
2003 & 490 & 662 & 2262 \\
2004 & 685 & 1577 & 3461 \\
2005 & 935 & 2526 & 5165 \\
2006 & 1090 & 4075 & 6189 \\
2007 & 1838 & 4351 & 7137 \\
2008 & 2268 & 4869 & 7241 \\
2009 & 2588 & 4653 & 8343 \\
2010 & 3250 & 5093 & \\
\hline
\end{tabular}

Kaynak: TPE, > http://www.turkpatent.gov.tr/portal/default.jsp > ve <http://www.universitetoplum.org/summary.php3?id=217>, 10.19.2010.

Tablo: 3

En Çok Patent Başvurusu Yapan İlk 20 Firma (2009 Yılı)

\begin{tabular}{|c|c|c|c|c|}
\hline Sira & Şirket & Ülke & 2008 & 2009 \\
\hline 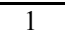 & Panasonic & Japonya & 1629 & 1891 \\
\hline 2 & Huawei Technologies & Çin & 1737 & 1847 \\
\hline 3 & Bosch & Almanya & 1273 & 1586 \\
\hline 4 & Koninkluke Philiphs Elek. & Hollanda & 1551 & 1295 \\
\hline 5 & Qualcomm Incorporated & $\mathrm{ABD}$ & 907 & 1280 \\
\hline 6 & T. Ericsson & İsveç & 984 & 1240 \\
\hline 7 & LG & Kore & 992 & 1090 \\
\hline 8 & NEC & Japonya & 825 & 1069 \\
\hline 9 & Toyota & Japonya & 1364 & 1068 \\
\hline 10 & Sharp & Japonya & 917 & 997 \\
\hline 11 & Siemens & Almanya & 1089 & 932 \\
\hline 12 & Fijutsu & Japonya & 984 & 817 \\
\hline 13 & Basf Aktiengesellschaft & Almanya & 721 & 739 \\
\hline 14 & 3M Innovative Proporties & $\mathrm{ABD}$ & 663 & 688 \\
\hline 15 & Nokia & Finlandiya & 1005 & 663 \\
\hline 16 & Microsoft & $\mathrm{ABD}$ & 805 & 644 \\
\hline 17 & Samsung & Kore & 639 & 596 \\
\hline 18 & NXP B.V & Hollanda & 407 & 593 \\
\hline 19 & Mitsubishi & Japonya & 503 & 569 \\
\hline 20 & HP & $\mathrm{ABD}$ & 496 & 554 \\
\hline
\end{tabular}

Kaynak: Dünya Fikri Mülkiyet Teşkilatı (WIPO) İstatistikleri, 2009,

<http://www.wipo.int/pressroom/en/articles/2010/article_0003.html>,08.09.2010. 
Tablo: 3'ten görüldüğü üzere dünyada en çok patent başvurusu yapan ilk 20 firmanın altısı Japonya dördü ise ABD firmalarıdır. Diğer bir değişle, dünyada en çok patent başvurusu yapan ilk 20 şirketin yarısını ABD ve Japon firmaları oluşturmaktadır.

Patent hakkı koruması çerçevesinde marka yaratımlarında en önemli hususlardan biri; markanın tescil edilmesi ve bu markanın aynısının ya da bir benzerinin bulunup, bulunmadığının tespit edilmesidir. Markalar 10 yıl için tescil edilmekde ve her 10 yılın bitiminden önce yenileme işlemi yapılmaktadır. Fikri hakların korunması ve etkili bir patent sistemi, markaların güçlenmesine yardımcı olmaktadır (Türkiye Patent Enstitüsü Stratejik Planı, 2007-2011).

Dünyada 2009 yllında en değerli 25 marka Tablo: 4'te sunulmuştur.

Tablo: 4

Dünyada 2010 Yılının Değerli 25 Markası

\begin{tabular}{|c|c|c|c|c|c|c|c|}
\hline $\begin{array}{c}2010 \\
\text { Sirası } \\
\end{array}$ & $\begin{array}{c}2009 \\
\text { Sirasi } \\
\end{array}$ & Marka & Ülke & Sektör & $\begin{array}{c}2009 \text { Değeri } \\
(\$)\end{array}$ & $\begin{array}{c}2010 \text { Değeri } \\
(\$)\end{array}$ & $\begin{array}{l}\text { Marka Değerindeki } \\
(\%) \text { Değişim } \\
\end{array}$ \\
\hline 1 & 1 & CocaCola & $\mathrm{ABD}$ & İçecek & 68734 & 70452 & $2 \%$ \\
\hline 2 & 2 & IBM & $\mathrm{ABD}$ & Bilgisayar & 60211 & 64727 & $7 \%$ \\
\hline 3 & 3 & Microsoft & $\mathrm{ABD}$ & Bilgisayar & 56647 & 60895 & $7 \%$ \\
\hline 4 & 7 & Google & $\mathrm{ABD}$ & İnternet & 31980 & 43557 & $36 \%$ \\
\hline 5 & 4 & General Elec. & $\mathrm{ABD}$ & Genel & 47777 & 42808 & $-10 \%$ \\
\hline 6 & 6 & McDonald & $\mathrm{ABD}$ & Restoran & 32275 & 33578 & $4 \%$ \\
\hline 7 & 9 & Intel & $\mathrm{ABD}$ & Bilgisayar & 30636 & 32015 & $4 \%$ \\
\hline 8 & 5 & Nokia & Finlandiya & Elektronik & 34864 & 29495 & $-15 \%$ \\
\hline 9 & 10 & Disney & $\mathrm{ABD}$ & Medya & 28447 & 28731 & $1 \%$ \\
\hline 10 & 11 & $\mathrm{HP}$ & $\mathrm{ABD}$ & Bilgisayar & 24096 & 26867 & $12 \%$ \\
\hline 11 & 8 & Toyota & Japonya & Otomobil & 31330 & 26192 & $-16 \%$ \\
\hline 12 & 12 & Mercedes & Almanya & Otomobil & 23867 & 25179 & $6 \%$ \\
\hline 13 & 13 & Gillette & $\mathrm{ABD}$ & Kişisel Bakım & 22841 & 23298 & $2 \%$ \\
\hline 14 & 14 & Cisco & $\mathrm{ABD}$ & Bilgisayar & 22030 & 23219 & $5 \%$ \\
\hline 15 & 15 & BMW & Almanya & Otomobil & 21671 & 22322 & $3 \%$ \\
\hline 16 & 16 & Louis Vuitton & Fransa & Lüxs Eşya & 21120 & 21860 & $4 \%$ \\
\hline 17 & 20 & Apple & $\mathrm{ABD}$ & Bilgisayar & 15433 & 21143 & $37 \%$ \\
\hline 18 & 17 & Marlboro & $\mathrm{ABD}$ & Tütün & 19010 & 19961 & $5 \%$ \\
\hline 19 & 19 & Samsung & Kore & Elektronik & 17518 & 19491 & $11 \%$ \\
\hline 20 & 18 & Honda & Japonya & Otomobil & 17803 & 18506 & $4 \%$ \\
\hline 21 & 21 & $\mathrm{HM}$ & İsveç & Giyecek & 15375 & 16136 & $5 \%$ \\
\hline 22 & 24 & Oracle & $\mathrm{ABD}$ & Bilgisayar & 13699 & 14881 & $9 \%$ \\
\hline 23 & 23 & Pepsi & $\mathrm{ABD}$ & İçecek & 13706 & 14061 & $3 \%$ \\
\hline 24 & 22 & American Exp. & $\mathrm{ABD}$ & Finansal Hiz. & 14971 & 13944 & $-7 \%$ \\
\hline 25 & 5 & Nescafe & İsviçre & İçecek & 13317 & 12753 & $-4 \%$ \\
\hline
\end{tabular}

Kaynak: Interbrand, 2010, <http://www.interbrand.com/en/knowledge/best-global-brands/best-global-brands2008/best-global-brands-2010.aspx>, 03.02.2010.

Tablo: 4'ten de görüldüğü üzere 2009 yılı itibariyle daha önce patent başvurusu yapmış ve aldıkları bu patent hakları sayesinde kendi markalarını yaratmış ilk 25 markanın 
16'sı ABD firması olmuştur. CocaCola, IBM ve Microsoft markaları da 2009 ve 2010 yıllarının en değerli ilk üç markaları olmuşlardır.

$\mathrm{Bu}$ çalışmanın amacı Türkiye gibi gelişmekte olan bir ekonomide fikr-i mülkiyet haklarının ekonomik olgu ve olaylar üzerindeki etkisinin analiz edilmesi ve bu doğrultuda oluşturulacak ekonomik politikalara katkıda bulunulması amaçlanmıştır.

\section{Literatür}

Thompson ve Rushing (1996) Ar\&Ge çalışmalarının patent ile koruma altına alındığında, patentlerin ekonomik büyümenin bir belirleyicisi olabileceğini savunmuştur. Katı patent kanunları ekonomik büyüme üzerinde daha etkili olabileceği gibi inovasyon çalışmalarının ise ekonomik büyümenin motoru olduğu belirtilmiştir (Thompson ve Rushing, 1996).

Charles ve Williams (2000) tarafindan yapılan çalışmada patent koruma sürelerinin önemine değinmiş, firmaların tekel kârını ne kadar devam ettirmesi gerektiğine vurgu yapılmıştır. Yine bu çalışmada patent sürenin 17 yıldan 20 yıla kadar olması konusunda dünya ticaret örgütü ile aynı görüşü paylaşılmıştır (Jones ve Williams, 2000).

Atun vd., (2006) çalışmada patentlerin ekonomik büyüme içerisinde önemli bir yer teşkil ettiğini ortaya koymuşlardır. Özellikle Ar\&Ge'nin patent içeren sektörleri yakından etkilediği de belirtilmiştir. Ayrıca bu çalışmada patentlerin ticaret yaratıcı etkisi, verimliliğe olan katkısı ve karlılık üzerine yaptığı etki üzerinde durulmuştur (Atun ve Wild, 2006).

Chu (2007) Ar\&Ge çalışmalarının patent hakları ile korunduğu takdirde toplam faktör verimliliğini arttırıcı özelliğine dikkat çekmiştir. İktisadi büyüme üzerinde ortaya çıkan bu pozitif etki aynı zamanda refah artışı da sağlamaktadır (Chu, 2007).

Hu ve Png (2009) 1981-2000 yıllarını kapsayan döneme ilişkin patent haklarının seksenli yıllarla doksanlı yıllar arasında ekonomik büyümeyi, doksanlı yıllar ile iki binli yıllar arası döneme göre büyümeden daha az etkilediğini ortaya koymuşlardır. $\mathrm{Bu}$ durum patent kanunların katıllı̆ı ile açıklanmıştır. Ayrıca bu çalışmada patent haklarının ticaret yaratıcı etkisi ve insan kaynaklarını geliştirici etkisi üzerinde durulmuştur (Hu ve Png, 2009).

WIPO (2010) tarafından yapılan çalışmada patent koruması firmaya Ar\&Ge maliyetlerini ve yatırımlarını telafi etme imkânı verdiğini savunmaktadır (WIPO, 2010). Yine Jones vd., (1998) tarafından yapılan çalışmaya göre patent koruması firmalara belirli bir süre monopol gücü vermektedir. Bu sayede firmaların kısa dönemde kârları daha yükseğe taşıyarak Ar\&Ge maliyetlerini telafi edebilmektedir (Jones ve Williams, 1998). 


\section{Uygulama}

\subsection{Veri Seti}

Türkiye'de Patent harcamaları ile ekonomik büyüme arasındaki ilişki zaman serisi ekonometrisi teknikleriyle ("Johansen eş-bütünleşme test"² yaklaşımı gibi) incelenmiştir. 1990:1-2010:4 dönemini kapsayan veriler kullanılarak Eş-bütünleşme ve Granger nedensellik ile analiz edilmiştir. $\mathrm{Bu}$ amaçla, değişkenlerin doğal logaritmaları alınmış ve uygun gecikme sayısı da AkaikeBilgi Kriterine ( $\mathrm{AIC}^{3}$ ) göre belirlenmiştir. Makro ekonomik değişkenlerin kullanıldığı çalışmalarda serilerin doğal logaritmasını alma işlemi yapılmasının sebepleri düzeyde üstel bir büyüme gösteren serinin logaritması alındığında büyümenin lineer hale dönüşmesidir. Logaritmanın alınması ile varyans stabilize (varyansın gösterimi daha kararlı hale getirilmesi veya sabitlenmesi) olmakta ve aykırı gözlemlerin etkileri azaltılmaktadır ${ }^{4}$. Ayrıca karakteristik köklerin sıfıra eşit olup olmadığı, dolayısıyla koentegrasyon ilişkisinin varlığının irdelenmesi için Johansen testi yapılmaktadır.

Daha sonra durağanlık ve eş-bütünleşme araştırılmış ve Johansen eş-bütünleşme testlerinde kullanılmak üzere iki önemli istatistik olan "iz" istatistiği ve "maksimum öz değer" istatistiğinden faydalanılmıştır. İz istatistiğinde test edilecek hipoteze ait en fazla "r adet eş-bütünleşik vektör" olup olmadığı araştırılmıştır. Öz-değer istatistiğinde ise "r+1 adet eş-bütünleşik vektör vardır” alternatif hipotezi test edilmiştir.

Çalışmada kullanılan patent harcamaları ve ekonomik büyüme verileri 1990:12010:4 dönemini kapsamaktadır. Bu veriler TÜİK kaynaklarından temin edilmiştir.

Çalışmada kullanılan patent (lpat) değişkeni logaritmik hale dönüştürülmüş ve büyüme oranı (EB) da reel hale getirilmiştir. EB, GSYİH (Gayri Safi Yurtiçi Hâsıla) serisinin bir önceki yıla göre değişimini ifade etmektedir. Bu serilerin 1990:1-2010:4 yıllarını içerir seyri Şekil: 2'de gösterilmiştir.

2 Soren, Johansen, "Statistical Analysis of Cointegrated Vectors", Journal of Economic Dynamics and Control, 12, 1988, pp. 231-254.

Soren Johansen and Katarina Juselius, "Maximum Likelihood Estimation and Inference on Cointegration: With Applications to the Demand for Money”, Oxford Bulletin of Economics and Statistics, 52, 1990, pp.169210 .

Soren Johansen, "Estimation and Hypothesis Testing of Cointegrated Vectors in Gaussian Vector Autoregressive Models", Econometrica, S. 58-59, 1991, pp. 165-88-1551-1580.

3 AIC: Akaike Bilgi Kriteri.

4 Franses P.H. and McAleer M., Cointegration Analaysis of Seasonal Time Series, Journal of Economic Surveys, 12(5), 1998, p. 654. 
Şekil: 2

Patent ve İktisadi Büyüme Değişkenleri (1990:1-2010:4)

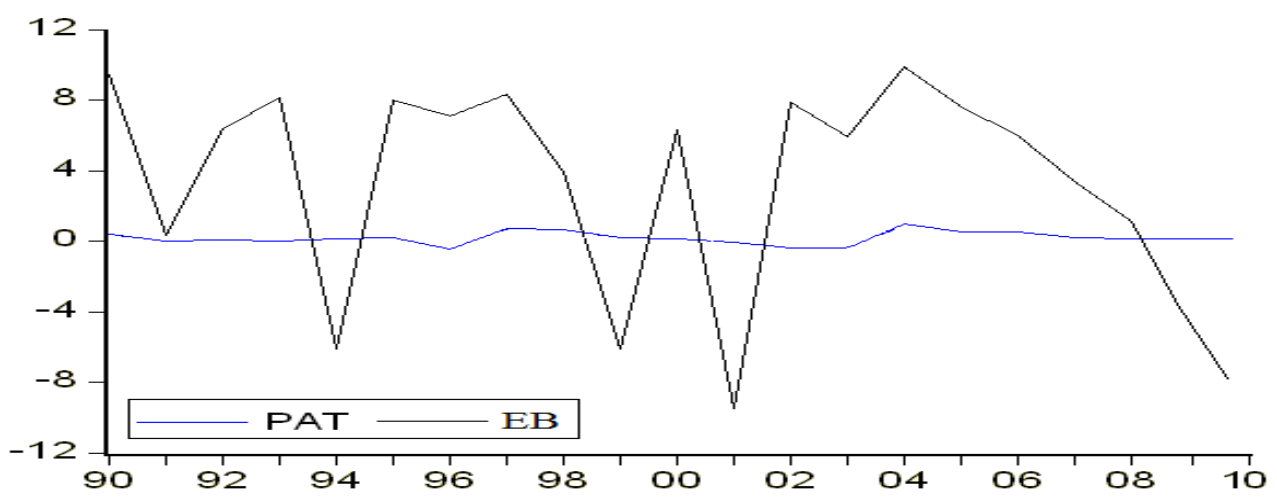

Genişletilmiş Dickey-Fuller (1979) (Augmented Dickey-Fuller (ADF)) ve Phillips-Perron (1988) (PP) testleri birim kök ve durağanlık sınamaları için kullanılmaktadır. ADF ve PP testleri sayesinde serilerin boş hipotezi (durağan olmadığı) test edilmektedir. Boş hipotezin reddi durumunda bu serilerin durağan olduğu sonucuna varılmaktadır. Diğer bir ifade ile seriler durağan bir yapıya sahip değilse ve sahte regresyon problemi ortaya çıkıyorsa, o zaman bu yolla elde edilen sonuçlar ve ele alınan büyüklükler arasında gerçek bir ilişkiden bahsedilmez (Granger ve Newbold, 1974).

Serileri ortaya çıkaran skolastik süreçlerin durağan olamayabileceğinden özellikle makro ekonomik serilerin durağanlık testlerinden geçirilmektedir. Seriler bu şokların karakteristiğine göre trend veya mevsimsel dalgalanma özelliği gösterebilmektedir. Öyle ki trend ve mevsimsellik gösteren seriler durağan değildir. Dolayısıyla serilerin skolastik kısmı elimine edilmez ise yanıltıcı regresyon ile karşılaşılabilir. Gerçek ilişkinin test edilebilmesi için serilerin trend etrafında durağan karaktere sahip olması arzulanır. $\mathrm{Bu}$ nedenle birim kök testleri serilerin durağanlık testlerinden geçirilmesi adına önem taşımaktadır.

Eğer seriler aynı dereceden durağan çıkarsa bu seriler eş-bütünleşme testlerine tabii tutulur. Eş-bütünleşme testi için "Johansen maksimum likelihood" ve "iz değerleri" araştırılmaktadır (Johansen, 1988). Johansen testi Vector Autoregressive (VAR) temelli bir test olmakla birlikte eş-bütünleşme ilişkisinin araştırılmasında kullanılmaktadır. Bu değer eş-bütünleşme vektör sayısını belirlemede yardımcı olmaktadır. İz testi de eş-bütünleşik olmuş vektör sayısını yani (r) $0,1, \ldots$ eşit veya küçük olduğu sıfır hipotezini test etmekte kullanılmaktadır. İz değerinin kritik değerden yüksek çıkması, iz testiyle eş-bütünleşme vektör sayısının her bir durum için boş hipotezlerin reddedilmesi anlamına gelmektedir. Örneğin $\mathrm{r}=0$ sıfir hipotezinin reddedilmesi 1 eş-bütünleşme vektörünün bulunduğunu; $r \leq 1$ 
sıfır hipotezinin reddedilmesi 2 eş-bütünleşme vektörünün bulunduğunu göstermektedir. $\mathrm{r}=0$ sıfır hipotezinin reddedilmemesi, değişkenler arasında eş-bütünleşme vektörünün bulunmadığı anlamını taşımaktadır.

\subsection{Hata Düzeltme Modeli}

Değişkenler arası uzun dönemli bir ilişkiden bahsedilmesi, eş-bütünleşme ilişkisinin varlığı anlamına gelir. Bu durum aynı zamanda en az tek yönlü bir nedensellik ilişkisinin de habercisidir. Yani hata düzeltme modeli (ECM) eş-bütünleşik olmuş seriler arasında kısa ve uzun dönemli ilişkilerin varlığını test etmede kullanılır. Hata düzeltme terimi eş-bütünleşme ilişkisinden uzun dönemde elde edilir. Her iki denklemde içsel değişkendeki değişim sadece gecikme uzunluğundan değil, aynı zamanda geçmiş dönemlerinden de etkilendiğinden nedensellik durumu ve yönü test edilebilir.

Hata düzeltme modeli (1) ve (2) numaralı denklem yardımıyla şu şekilde gösterilebilir:

$$
\begin{aligned}
& \Delta \mathrm{EB}_{\mathrm{t}}=\alpha_{1}+\sum_{i=1}^{p} \beta_{l i} \Delta \mathrm{EB}_{\mathrm{t}-\mathrm{i}}+\sum_{i=1}^{p} \varphi_{l i} \Delta \mathrm{lpat}_{\mathrm{t}-\mathrm{i}}+\sigma_{l i} \psi_{t-1}+\varepsilon_{l t} \\
& \Delta \mathrm{lpat}_{\mathrm{t}}=\alpha 2+\sum_{i=1}^{p} \beta_{2 i} \Delta \mathrm{EB}_{\mathrm{t}-\mathrm{i}}+\sum_{i=1}^{p} \varphi_{2 i} \Delta \mathrm{lpat}_{\mathrm{t}-1}+\sigma_{2 i} \psi_{t-1}+\varepsilon_{2 t}
\end{aligned}
$$

(1) ve (2) numaralı denklemlerde yer alan EB ve lpat sirasiyla ekonomik büyüme ve patent verilerini göstermektedir. (1) ve (2) numaralı denklemlerde patent başvuruları için lpat tahmin edilecektir. Eğer bir eş-bütünleşme ilişkisine rastlanmazsa (1) ve (2) numaralı denklemler hata düzeltme terimi olmadan tahminleri yapılır. Yani bir VAR modeli kurulur. Hata düzeltme terimi içermeyen bu denklemlere Granger nedensellik testleri yapılırken Wald testi kullanılmaktadır. $\mathrm{Bu}$ test sayesinde ulaşılan $\chi^{2}$ istatistik değerleri hesaplanabilir.

\subsection{Uygulama Sonuçları}

Çalı̧̧mada kullanılan değişkenler arasında uzun dönemli bir ilişkinin varlı̆̆ını test etmek için yapılan testler sonucu serilerin ancak birinci farkları alındıktan sonra 
durağan olduğu görülmüştür. Eş-bütünleşme sayesinde seriler bağımsız olarak durağan olmasalar da doğrusal bileşenleri durağan olabilmektedir.

Tablo: 5 çalışmada kullanılan değişkenler için ADF ve PP test sonuçlarını göstermektedir:

Tablo: 5

\section{Durağanlık Test Sonuçları}

\begin{tabular}{|c|c|c|c|c|c|}
\hline \multirow{2}{*}{\multicolumn{2}{|c|}{ Değişkenler }} & \multicolumn{2}{|c|}{ Sabit Terimli } & \multicolumn{2}{|c|}{ Sabit Terim + Trend } \\
\hline & & $\mathrm{ADF}$ & PP & $\mathrm{ADF}$ & $\mathrm{PP}$ \\
\hline \multirow{2}{*}{ Değişkenlerin Düzey Değerleri } & lpat & $-3.62598(1)$ & $-3.609038(1)$ & $-3.65810(1)$ & $-3.60738(1)$ \\
\hline & EB & $-3.80813(4)$ & $-3.801354(1)$ & $-3.68400(4)$ & $-3.67921(1)$ \\
\hline \multirow{3}{*}{ McKinnon $^{5}$ Kritik Değerleri } & $\% 1$ & \multirow{3}{*}{\multicolumn{2}{|c|}{$\begin{array}{l}-3.831511 \\
-3.029970 \\
-2.655194\end{array}$}} & \multirow{3}{*}{\multicolumn{2}{|c|}{$\begin{array}{l}-3.857386 \\
-3.040391 \\
-2.660551\end{array}$}} \\
\hline & $\% 5$ & & & & \\
\hline & $\% 10$ & & & & \\
\hline \multirow{2}{*}{ Değişkenlerin Birinci Farkları } & $\Delta$ lpat & $-5.54138(2) *$ & $-10.17058(2) *$ & $-5.36113(2) *$ & $-9.73668(2) *$ \\
\hline & $\Delta \mathrm{EB}$ & $-8.56193(2) *$ & $-8.915249(2) *$ & $-8.36374(2) *$ & $-8.75007(2) *$ \\
\hline \multirow{3}{*}{ McKinnon Kritik Değerleri } & $\% 1$ & \multirow{3}{*}{\multicolumn{2}{|c|}{$\begin{array}{l}-4.532598 \\
-3.673616 \\
-3.277364\end{array}$}} & \multirow{3}{*}{\multicolumn{2}{|c|}{$\begin{array}{l}-4.667883 \\
-3.733200 \\
-3.310349 \\
\end{array}$}} \\
\hline & $\% 5$ & & & & \\
\hline & $\% 10$ & & & & \\
\hline
\end{tabular}

lpat: Patent Harcamalarl, leb:İktisadi Büyüme

ADF: Genişletilmiş Dickey Fuller (Augmented Dickey-Fuller), PP: Phillips-Perron

*** ve *ADF ve PP testlerinde serilerin birim kök taşıdığı boş hipotezinin sırasıyla $1 \%$ ve $10 \%$ seviyelerinde reddedildiğini ifade etmektedir.

Not: lpat, leb, Patent ve İktisadi Büyüme değişkenlerinin seviye değerlerini göstermektedir. $\Delta$ değişkenlerin birinci farkların ifade etmektedir. Optimal gecikme uzunluğu ADF testi için Akaike bilgi kriteri (AIC) kriterine göre belirlenmiş ve parantez içinde gösterilmiştir. Diğer taraftan PP testinde band aralığı Newey-West metoduyla tespit edilmiştir.

Tablo: 5'den de görüldügü üzere ADF için test istatistiği düzeyde lpat ve leb için sırasıyla (-3.62598) ve (-3.80813) iken PP için test istatistiği düzeyde lpat ve leb için sirasıyla (-3.609038) ve (-3.801354) değerleri $\% 1, \% 5$ ve $\% 10$ anlamlılık düzeylerinde Mac Kinnon kritik değerlerinden mutlak olarak küçük olduğundan Ho hipotezi reddedilemez ve serinin durağan olmadığına işarettir. Birinci farkları alınan serilerin ADF ve PP değerleri için $\% 1, \% 5$ ve $\% 10$ anlamlılık düzeylerinde Mac Kinnon kritik değerlerinden mutlak olarak büyük olduğu için Ho hipotezi reddedilir ve serilerin birim kök sorunu bulunmadığı ve serilerin durağan olduğu kabul edilir.

Çalışmada kullanılan patent ve ekonomik büyüme değişkenlerinin aynı derecede entegre I(1) olması sebebiyle eş-bütünleşme testlerine geçilmiştir. Değişkenler arasındaki

5 James G. Mackinnon, “Critical Values for Cointegration Tests”, in Engle, R.F. and Granger, C.W.J (eds), Long-run Economic Relationship, Oxford, 1991. 
eş-bütünleşme ilişkisinin tespiti için Johansen-Juselius (JJ) yönteminden faydalanılmıştır. Eş-bütünleşme test sonuçları Tablo: 6'da gösterilmiştir.

Tablo: 6

Eş-bütünleşme Test Sonuçları

\begin{tabular}{|c|c|c|c|c|c|c|c|c|}
\hline $\begin{array}{l}\text { eğişkenler } \\
\text { lpat, EB }\end{array}$ & & & & & & & & \\
\hline Ho & Özdeğer & $\begin{array}{l}\text { İz } \\
\text { İstatistiğ } \mathrm{i}\end{array}$ & $\begin{array}{c}\text { \%5 Kritik } \\
\text { Değer }\end{array}$ & p-değ. & HO & $\begin{array}{c}\text { Maksimum Özdeğer } \\
\text { İstatistiği }\end{array}$ & $\begin{array}{l}\text { \%5 Kritik } \\
\text { Değer }\end{array}$ & p-değ. \\
\hline $\mathrm{r}=\mathrm{c}$ & & $37.02743 * * *$ & 15.4947 & 0.0011 & $\mathrm{r}=0$ & $28.79365^{* * *}$ & 14.2646 & 0.0001 \\
\hline $\mathrm{r} \leq 1$ & 0.367093 & $8.233784^{* * *}$ & 3.84147 & 0.0041 & $r \leq 1$ & $8.233784 * * *$ & 3.84147 & 0.0041 \\
\hline
\end{tabular}

*** boş hipotezin \%1 anlamlllık düzeyinde reddedildiğini göstermektedir

$r$ koentegrasyon vektörünün sayısını göstermektedir.

Optimal gecikme uzunluğu AIC ve Schwarts Bayesian Criteria'ya (SBC) göre belirlenmiş ve parantez içinde belirtilmiştir.

Tablo: 6'dan da görüldüğü üzere lpat ve leb serileri için uzun dönemli bir ilişkinin varlığının tespit edilmiş ve Ho hipotezi reddedilmiştir. İz ve Maksimum özdeğer istatistik değerlerinin \%5 Kritik değerinden büyük olduğu durumlar sırasıyla şu şekildedir. (lpat»leb)'dir.

Eş-bütünleşme testlerinden sonra nedensellik testi yardımıyla değişkenler arasındaki uzun dönemli ilişkisinin yönü (önemi) tespit edilmektedir. Ayrıca (1) ve (2) nolu denklemler içerisinde yer alan diğer bir nedensellik (kısa dönem ilişkisi) olan hata düzeltme teriminin (ECT, Error Correction Term) tahmini de yapılmaktadır. Hata düzeltme teriminin katsayısı uzun dönem dengesinden ne kadar sapma olduğunu göstermektedir. Örneğin, $\theta=$ sıfırsa, patent harcamaları önceki dönemde uzun dönem dengesinden bir sapmaya izin vermemektedir. Bu ancak basit bir t-testi kullanılarak elde edilir. Kısa ve uzun dönem ayrımları için de ayrıca F-testi uygulanarak bu değişkenler sınanmaktadır. Sonuçlar Tablo: 7'de sunulmuştur.

Tablo: 7

\section{Hata Düzeltme Modeli ve Granger Nedensellik Testi}

1990:1-2010:4

Gecikme Sayısı: 2

Sifir Hipotezi:

EB ------------- PAT

F İstatistiği

Katsay1

PAT -------------- EB

1.82716

Uygun gecikme uzunluğu AIC ve SBC kriterine göre belirlenir.

** ve ***\%5 ve \%1 anlamlllk düzeyini göstermektedir.

Tabloda yer alan değerler $X^{2}$ istatistik değerleridir.

$p=$ optimal gecikme sayıs .

$\psi t-1(t)=$ Hata düzeltme terimi katsayısının $t$ istatistiği değeridir. 
Tablo: 7'den de görüldüğü üzere hata düzeltme modeli ve Granger nedensellik test sonuçları ekonomik büyüme ile patent başvuruları arasında da tek yönlü (9.82521) bir iliş̧i mevcuttur ve bu ilişskinin yönü patent başvurularından ekonomik büyümeye doğrudur. Ayrıca hata düzeltme terimi katsayısının (-1.476896) istatistiki olarak anlamlı olması ise uzun dönem etkinin mevcut olduğunu göstermektedir. Test sonuçlarına göre değişkenler arası Granger nedensellik ilişkileri görsel olarak Şekil 4'de gösterilmiştir.

Şekil: 4

Patent ve İktisadi Büyüme Değişkenlerinin Nedensellik Yönleri

\section{Ekonomik Büyüme \\ Patent}

Şekil: 5

Patent ve İktisadi Büyüme Değişkenlerine İlişkin Tepki Grafikleri (Impulse Response)
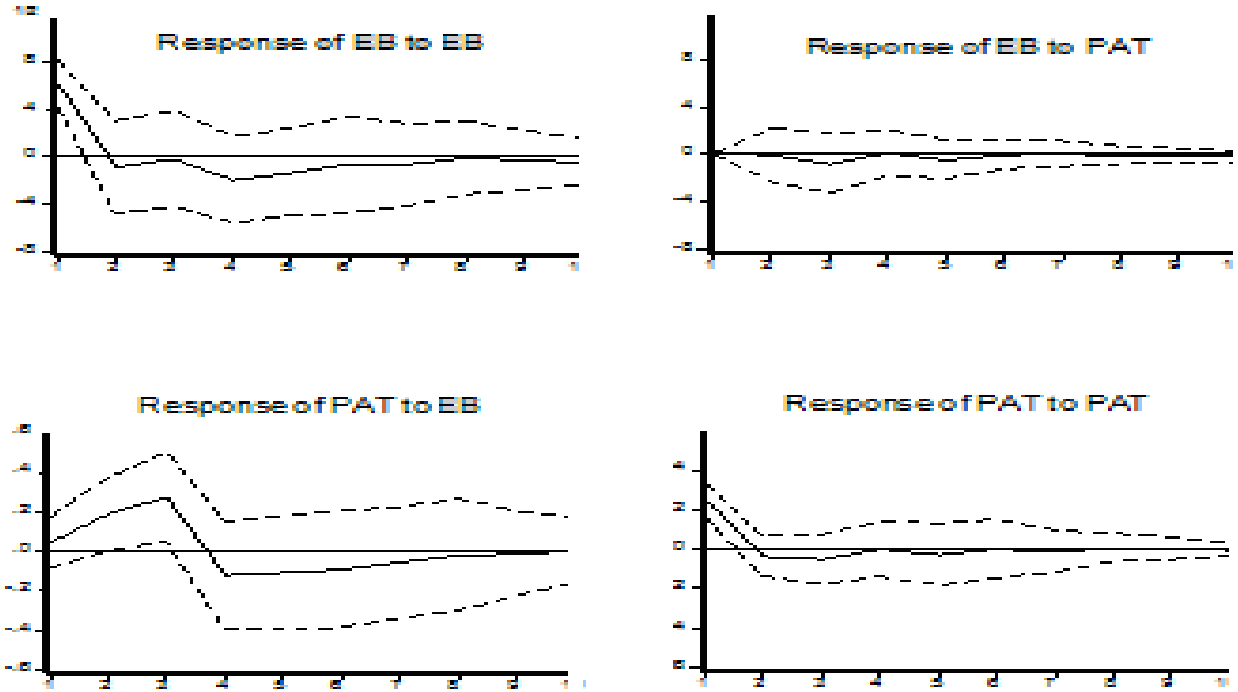

Not: “Impulse responses" 21 ylllı bir zaman dönemine yayllmakta ve uzun dönem eş-bütünleşme analizlerini göstermektedir. Ayrıca değişkenler arasında pozitif bir korelasyonun varlığını açıklamada kullanılmaktadır.

Şekil 5'den de görüleceği üzere, örneğin ekonomik büyümedeki bir standart hatalık şok karşısında patent harcamalarının gösterdiği tepki 2. döneme kadar negatif, 3 . dönemde pozitif olmuş ve kısa bir dalgalanmanın ardından 5. dönemden itibaren uzun 
dönem denge değerine dönmüştür. Diğer bir ifade ile ekonomik büyümede meydana gelen bir standart sapmalık bir şok patent harcamaları üzerinde azaltıcı bir etkiye neden olmaktadır.

\section{Sonuç}

Çalışmada Türkiye'de patent harcamaları ve ekonomik büyüme arasındaki ilişki zaman serisi ekonometrisi teknikleriyle incelenmiştir. 1990:1-2010:4 dönemini kapsayan veriler Eş-bütünleşme ve Granger nedensellik ile analiz edilmiştir. Elde edilen bulgular sonucunda, patentten (9.82521) ekonomik büyümeye tek yönlü Granger nedensellik ilişkisinin olduğu belirlenmiştir. Bu sonuçlar, literatürde Narayan ve Smyth (2006)'in çalışmasında elde edilen bulguları destekler niteliktedir. Ayrıca, hata düzeltme katsayılarının negatif ve anlamlı çıkması da cari dönemdeki dengesizliğin uzun dönem dengesine ayarlanma hızının oldukça yüksek olduğunun bir işarettir. Öte yandan, kısa dönemde patent harcamalarındaki bir artışın ekonomik büyüme üzerinde pozitif bir etki yarattı̆̆ 1 tespit edilmiştir.

Sürdürülebilir bir ekonomik büyüme için patent harcamalarının planlı bir şekilde yürütülmesi gerekliliği bu çalışma ile ortaya konmuştur. Böylece, patent koruması ve teknolojinin etkin kullanımı ile yüksek teknoloji üretebilen yeni firmalar ortaya çıkabilecektir. Bu sayede firmalar bilgiyi, teknolojik ürünlere dönüştürmek suretiyle sektörler arası teknoloji transferini kolaylaştırabileceğinden patent faaliyetleri ve bu faaliyetlerin geri dönüş oranının artması teknolojinin ihracat oranı üzerinde olumlu bir etki oluşturacaktır. Bu durum ülkenin dışa bağımlılığının azaltılmasına yardımcı olurken bölgesel ve yerel ekonomi yeniden yapılanarak iktisadi faaliyetlerin çeşitlenmesine neden olacak ve buna bağlı olarak iktisadi verimlilik de artırabilecektir. Ayrıca, patent koruması çalışmalarının ekonomik değere dönüşüp yenilikçi firmaların faaliyet göstermesi, yeni girişimcilerin yetişmesine ve istihdam olanaklarının artmasına yol açabilecetir. Yeni istihdam alanlarının ortaya çıkması ise beyin göçünün önlenmesine katkı sağlayabilecektir. $\mathrm{Bu}$ durum ekonominin sahip olduğu kaynakların daha verimli kullanılmasına dolayısıyla refah düzeyinin yükseltilmesine vesile olurken ülkenin de rekabet düzeyini yukarı seviyelere çekilebilecektir.

\section{Kaynakça}

Abacıoğlu, N. \& A.A. Dikmen (2005), "Meta Olarak İlaçta Sınaî ve Fikri Mülkiyet Rejiminin Ekonomi Politiği”, Türkiye Sosyalist İktisat Kongresi, 17-18 Aralık, İstanbul, s. 9.

Avrupa Patent Teşkilatı (EPO), < http://www.epo.org/aboutus/press/releases/archive/2010/20100427.html> , 10.02.2010. 
Atun, R. \& I.H.J. Wild (2006), “Innovation, Patents and Economic Growth”, Discussion Paper, Imperial Colloge of London and Tanaka Businesss School, p. 5.

Ayhan, Ahmet (2002), Dünden Bugüne Türkiye'de Bilim ve Teknoloji ve Geleceğin Teknolojileri, İstanbul: Beta Yayınevi, s. 264.

Chu, A.C. (2007), "Economic Growth and Patent Policy: Quantifying the Effects of Patent Length on R\&D and Consumption", MPRA Paper, No. 5476, 1-36, <http://mpra.ub.unimuenchen.de/5476/1/MPRA_paper_5476.pdf>, 15.10.2010.

Dickey, D.A. \& W.A. Fuller (1979), "Distribution of the Estimators for Autoregressive Time Series with a Unit Root", Journal of the American Statistical Association, 74, 427-431.

Dünya Patent Teşkilatı (WIPO) İstatistikleri (2010),

$<$ http://www.wipo.int/ipstats/en/statistics/patents/>, 10.02.2010.

European Commission (2010),

$<$ http://ec.europa.eu/internal_market/indprop/patent/index_en.htm\#patent>, 30.03.2010.

Güçer, S. (2005), "Rekabet Hukukunda Hakim Durumun Kötüye Kullanılması Çerçevesinde Sınai Mülkiyet Hakları”, Rekabet Kurumu Lisansüstü Tez Serisi, S. XIII, s. 6.

Granger, C.W.J. \& P. Newbold (1974), "Spurious Regressions in Econometrics”, Journal of Econometrics, (2), 111-120.

Hu, A. \& I. Png (2009), "Patent Rights and Economic Growth: Cross-Country Evidence”, CELS 2009 4th Annual Conference on Empirical Legal Studies Paper, p. 1.

Johansen, S. (1988), "Statistical Analysis of Cointegrated Vectors", Journal of Economic Dynamics and Control 12, 231-254.

Johansen, S. \& K. Juselius (1990), "Maximum Likelihood Estimation and Inference on Cointegration: With Applications to the Demand for Money", Oxford Bulletin of Economics and Statistics, 52, 169-210.

Jones, C. \& J. Williams (1998), "Measuring the Social Rate of Return to R\&D”, Quarterly Journal of Economics, Vol. 113, 119-35.

Jones C.I. \& J.C. Williams (2000), "Too Much of a Good Thing? The Economics of Investment in R\&D”, Journal of Economic Growth, Vol. 5, 65-85.

Mackinnon, J.G. (1991), “Critical Values for Cointegration Tests”, in Engle, R.F. \& C.W.J. Granger (Eds), Long-run Economic Relationship, Oxford.

Narayan, P.K. \& R. Smyth (2006), "What determines migration flows from lowincome to highincome countries? An empirical investigation of Fiji-US Migration 1972-2001", Contemporary Economic Policy, 24(2), 332-342.

Phillips, P.C.B. \& P. Peron (1988), “Testing for a Unit Root in Time Series Regression”, Biometrika, $75(4), 335-46$.

Soyak, A. (2005), "Fikri ve Sınaî Mülkiyet Hakları: Tanımı, Tarihsel Gelişimi ve GOÜ’ler Açısından Önemi”, Legal Fikri ve Sinaî Haklar Dergisi, S. 1, 2005, 11-30. 
Cem IŞIK

T.C. Sağlık Bakanlığı Avrupa Birliği Koordinasyon Dairesi Başkanlığı (2010), Avrupa Birliği ve Sağlık Bakanlı̆̆ Uyum Çalışmaları,

$<$ http://sbu.saglik.gov.tr/Ekutuphane/kitaplar/abkdb2.pdf >, 08.10.2010.

Thompson, M.A. \& F.W. Rushing (1996), “An Empirical Analysis of the Impact of Patent Protection on Economic Growth”, Journal of Economic Development, 21(2), 61-77.

Türkiye Patent Enstitüsü, <http://www.e-kutuphane.teb.org.tr/pdf/tebhaberler/mart_nisan05/12.pdf>, 18.10.2010.

Türkiye Patent Enstitüsü, Türkiye Patent Enstitüsü Stratejik Planı (2007-2011), $<$ http://www.tpe.gov.tr/portal/duyurular/TPE_SP.pdf>, 02.09.2010.

Türkiye Patent Enstitüsü, Patent ve Faydalı Model Başvurularının Yıllara Göre Dağılımı, Türkiye Patent Enstitüsü Yayını, <http://www.turkpatent.gov.tr/portal/default.jsp>, 10.19.2010.

WIPO (2010), Economic Development and Patents, $<$ http://www.wipo.int/patentlaw/en/developments/economic.html>, 15.10.2010. 